\title{
Seleção para a residência médica da Universidade Federal do Rio de Janeiro: percepção dos candidatos sobre o modelo da prova
}

PALAVRAS-CHAVE

- Avaliação educacional.

- Internato e Residência.

- Aptidão.

- Competencia Clinica..

\section{Admissions to medical residency at the Federal University in Rio de Janeiro: perceptions by applicants concerning the test model}

Rosane Goldwasser ${ }^{\mathrm{I}}$

Vera Fonseca ${ }^{\mathrm{I}}$

Maria Stella Lobo ${ }^{\mathrm{I}}$

Alycia Coelho ${ }^{\mathrm{I}}$

Elizabeth Gomes dos Santos ${ }^{\mathrm{I}}$

Sylvia Maria Porto Pereira ${ }^{\mathrm{I}}$

\section{R E S U M O}

Este trabalho relata a opinião dos candidatos aprovados nos programas de residência médica da Universidade Federal do Rio de Janeiro (UFRJ) que concorreram às especialidades, sem pré-requisito, quanto ao modelo de prova, baseado nas modificações propostas pela comissão do processo seletivo 2005. Na elaboração das provas, foram utilizadas como referencial as Diretrizes Curriculares Nacionais do Curso de Graduação de Medicina e a Resolução da Comissão Nacional de Residência Médica. Um questionário estruturado, com questões fechadas, foi distribuído aleatoriamente aos candidatos aprovados nesse concurso. A maioria dos respondentes $(84,16 \%)$ avaliou como "muito boa" ou "boa" cada etapa do concurso, sendo que a prova prática presencial com pacientes obteve o melhor conceito. Os autores discutem as competências necessárias na atenção à saúde e que serviram de base para as principais modificações introduzidas no processo seletivo. Outro ponto relevante foi a importância da integração interdisciplinar da comissão de seleção. O alto índice de aprovação mostra que as mudanças realizadas foram pertinentes, e os graus atribuídos às diversas etapas do concurso podem contribuir para o aperfeiçoamento do processo seletivo e como instrumento de avaliação educacional dos recém-formados das faculdades de Medicina.

- Educational measurement.

- Internship and Residency.

- Aptitude.

- Clinical Competence.

Recebido em: 07/08/2006 Reencaminhado em: 07/05/2007 Reencaminhado em: 22/09/2007 Aprovado em: :27/10/2008 


\section{INTRODUÇÃO}

O processo de seleção e recrutamento de médicos qualificados para os Programas de Residência Médica é uma das maiores preocupações das instituições que promovem este tipo de treinamento. O concurso é extremamente competitivo, sobretudo para as especialidades de acesso direto, ou seja, sem pré-requisito, que contempla os egressos das faculdades de Medicina. Como todo processo intencional, a educação exige avaliação de resultados. Este processo, atualmente, assumiu maior vulto em face do número de vagas para residência médica em relação ao número de formandos. No Brasil, 415 instituições oferecem vagas para esse treinamento, sendo que $50,8 \%$ se concentram na Região Sudeste ${ }^{1}$.

O médico egresso da faculdade de Medicina deve ter formação generalista, humanista, crítica e reflexiva e estar apto a atuar no processo de saúde e doença, com ações de promoção, prevenção, recuperação e reabilitação da saúde ${ }^{2}$. Devem-se estruturar situações em que o aluno recém-formado possa demonstrar as competências adquiridas durante a formação acadêmica. Esse procedimento traz embutida a bagagem cognitiva, a destreza e a coerência na realização da tarefa, a capacidade de resolução das condições mórbidas prevalentes com aplicações adequadas dos métodos diagnósticos. Todos esses procedimentos incluem dimensões éticas e humanas e se traduzem na responsabilidade social do cidadão.

O processo seletivo para a residência médica da Universidade Federal do Rio de Janeiro (UFRJ) buscou contemplar, em todas as fases do concurso, as determinações das Diretrizes Curriculares Nacionais estipuladas pelo Conselho Nacional de Educação e pela Resolução da Comissão Nacional de Residência Médica, que dispõe sobre o processo de seleção pública dos candidatos aos Programas de Residência Médica ${ }^{2,3}$. As provas foram elaboradas por uma comissão interdisciplinar, composta de profissionais médicos/docentes do Hospital Universitário Clementino Fraga Filho (HUCFF), Instituto de Puericultura e Pediatria Martagão Gesteira (IPPMG), Instituto de Doenças do Tórax (IDT), Instituto de Psiquiatria (IPUB), Maternidade Escola, Instituto de Neurologia Deolindo Couto (INDC), Instituto de Genecologia (IG), pertencentes às cinco áreas básicas de conhecimento médico: Clínica Médica, Cirurgia Geral, Obstetrícia e Ginecologia, Pediatria, e Medicina Preventiva e Social. O processo seletivo se deu em duas fases: a primeira, eliminatória para os que não atingiram grau superior ou igual a cinco, constituída por prova objetiva, com questões de escolha múltipla; e a segunda (classificatória), prática. Para acompanhar a proposta do modelo de prova, foi elaborado um questionário a fim de conhecer a percepção dos candidatos sobre as modificações implantadas e verificar a convergência com os objetivos iniciais da comissão de seleção do concurso.

\section{MODELO DE PROVA}

A primeira fase consistiu em prova objetiva, com cem questões de escolha múltipla, embasada em situações de saúde e doenças prevalentes na população em geral, com ênfase nas características demográficas do nosso país, abrangendo as cinco áreas básicas de conhecimento médico exigido para as especialidades de acesso direto (Clínica Médica, Pediatria, Cirurgia Geral, Obstetrícia e Ginecologia, e Medicina Preventiva e Social). Para este fim, a comissão elegeu alguns temas centrais, baseando-se na prevalência e relevância. Foram elaborados casos clínicos e perguntas dentro dessas cinco especialidades básicas, além de questões sobre ética, promoção da saúde e prevenção de doenças. Esta prova era eliminatória e classificava candidatos para a segunda fase considerando no mínimo o dobro do número de vagas oferecidas às diversas especialidades do concurso.

A segunda fase, a prova prática, foi dividida em duas etapas. A primeira denominava-se prova de multimídia. Nessa etapa, os candidatos foram alocados aleatoriamente em anfiteatros com sistema de áudio e vídeo. Dois coordenadores da comissão de seleção, previamente treinados, conduziam a prova em cada sala. A projeção das provas era realizada simultaneamente em todas as salas, com tempo cronometrado para cada questão. Por meio do reconhecimento de situações quase reais demonstradas em vídeos, imagens e reportagens veiculadas pelos diversos meios de comunicação, $\mathrm{O}$ candidato respondia graficamente às questões objetivas, dentro das cinco áreas básicas do conhecimento médico. Foram selecionadas situações reais do dia-a-dia do estudante do internato médico. Alguns exemplos ilustrativos de vídeos didáticos utilizados: um parto normal, a avaliação ambulatorial de um lactente, procedimentos de assepsia e anti-sepsia, videoclipe de televisão com reportagem sobre tema selecionado em função da competência esperada para um médico recém-formado.

A segunda etapa consistiu em prova de habilidade e atitude, denominada prova presencial ou de beira do leito. A prova era aplicada a cada candidato individualmente por uma banca com três avaliadores e um paciente. O paciente era institucional, podendo estar localizado na enfermaria, ambulatório ou emergência. Após seu consentimento escrito, o paciente era submetido à anamnese e exame físico pelo candidato, que permanecia em observação não-interativa com a banca examinadora. Neste momento, os candidatos eram avaliados em relação a atitude, aspectos éticos e destreza na realização da coleta de dados e exame físico. Após a realização desta tarefa, o candidato era avaliado quanto ao raciocínio desenvolvido a partir dos dados coletados.

\section{METODOLOGIA}

Na semana que precedeu o início das atividades da residência médica, um questionário foi distribuído aleatoriamente aos candidatos aprovados no concurso para a residência médica da 
UFRJ que concorreram às vagas para as especialidades sem pré-requisito e que foram submetidos às três etapas do concurso. Os candidatos foram informados quanto ao objetivo do estudo e à não obrigatoriedade da resposta. Não foi exigida identificação dos candidatos nem das especialidades escolhidas. Houve parecer favorável da Comissão de Ética em Pesquisa do HUCFF.

Os candidatos foram inicialmente abordados quanto à avaliação global do processo seletivo. Em relação à prova objetiva, foram questionadas a relevância dos temas abordados e a capacidade de avaliar conhecimento. Quanto à prova de multimídia, também foram questionados sobre a relevância dos temas escolhidos e a capacidade de avaliar conhecimento para cada área (Clínica Médica, Obstetrícia e Ginecologia, Pediatria, Cirurgia Geral, e Medicina Preventiva e Social). A prova presencial foi analisada quanto à aptidão em avaliar habilidades e atitudes. As opções disponíveis para avaliação das provas foram definidas como muito bom (MB), bom (B), regular (R) e insuficiente (I).

\section{RESULTADOS}

Dos 50 questionários distribuídos, retornaram 31 respostas (62\%). A avaliação geral em relação ao concurso de residência está apresentada no Gráfico 1. Foi considerada como MB e B por $84,16 \%$ (39\% e $45,16 \%$, respectivamente) e R por $14,7 \%$ dos candidatos.

Em relação à relevância dos temas da prova escrita, 17 $(38,7 \%)$ candidatos deram o conceito MB, $12(54,8 \%)$ consideraram B e $2(6,4 \%)$ como R. Nesta mesma prova, em relação à avaliação do conhecimento, $12(54,8 \%)$ candidatos consideraram como MB, 18 (58,0\%) como B e 1 (3,2\%) como R (Gráfico 2).

$\mathrm{Na}$ avaliação da prova de multimídia, quanto à relevância dos temas abordados, 7 (22,5\%) candidatos consideraram MB, 16 $(51,6 \%)$ como B e 8 (25,8\%) como R (Gráfico 3). Quando questionada a capacidade de avaliar conhecimento para cada área básica, os resultados mostraram os seguintes conceitos: para Clínica Médica, 7 (22,5\%) MB; 19 (16,2\%) B; 4 (12,9\%) R; e 1 (3,2\%) I; para Cirurgia Geral, 6 (19,3\%) MB; 17 (54,8\%) B; e 8 (25,8\%) R; para Pediatria, 8 (25,8\%) MB; 16 (51,6\%) B; e 7 (22,5\%) R; para Obstetrícia e Ginecologia, 16 (51,6\%) MB; 14 (45,1\%) B; e 1 (3,2\%) R; para Medicina Preventiva e Social, 5 (16,1\%) MB; 15 (48,3\%) B; 10 (32,2\%) R; e 1(3,2\%) I (Gráfico 4).

A prova presencial diante de pacientes recebeu os seguintes conceitos: 25 (83,3\%) MB e $5(16,6 \%)$ B; um candidato não respondeu (Gráfico 5).

\section{DISCUSSÃO}

A residência médica foi instituída pelo Decreto nํำ 80.281 , de 5 de setembro de 1977, consistindo em uma modalidade de ensino de pós-graduação destinada a médicos, sob a forma de curso de especialização, funcionando em instituições de assistência à saúde, sob a orientação de profissionais médicos ${ }^{4}$. É considerada o padrão-ouro da especialização médica no País, estando credencia- dos 2.550 programas de residência médica. Em 2005, tais programas ofereceram cerca de 22 mil vagas (8.574 para médicos residentes do primeiro ano) e estão distribuídos em 415 instituições de saúde, concentradas, em sua maioria, na Região Sudeste $(50,8 \% \text { das vagas })^{1,3}$. Além de permitir a educação técnica, profissionalizante, em elevado nível - possibilitando a devolução, à sociedade, de especialistas -, a residência médica deve ser igualmente um foro destinado à consolidação da formação humanista do médico ${ }^{3}$.Com o desequilíbrio entre a demanda e a oferta de vagas, há necessidade de um processo seletivo. O processo de seleção para a residência médica, apesar de avaliar indiretamente o ensino da graduação das escolas médicas, difere da avaliação do graduando realizada pelo Ministério da Educação (MEC), que visa à instituição de ensino. Ele julga, além do conhecimento, outras competências que o médico deve preencher para cumprir as tarefas adequadas ao perfil da instituição à qual o profissional se candidata. Da mesma forma que as avaliações feitas ao longo da graduação, a avaliação do processo de seleção faz parte de critérios de qualificação do médico.

A formação do médico, segundo as Diretrizes Curriculares Nacionais, tem por objetivo dotar o profissional dos conhecimentos requeridos para o exercício de competências na atenção à saúde nos níveis individuais e coletivos. Além disso, esperam-se outras habilidades, que envolvem, além do exercício cognitivo, a capacidade de se comunicar adequadamente e promover acolhimento ao paciente, a seus familiares, seus colegas e à equipe de saúde. Essa estrutura deve incluir dimensões éticas e humanísticas, buscando integrar as dimensões biológicas, psicológicas, sociais e ambientais².

As competências pré-selecionadas pela comissão de seleção do concurso para a residência médica da UFRJ foram: o conhecimento científico, as habilidades, a atitude e os aspectos éticos. A prova que avalia o conhecimento promove a distinção entre os candidatos bons e os ruins. É uma competência que pode ser adquirida de modo passivo, por meio da leitura, nas aulas, nos cursos preparatórios. Esta observação pode ser comprovada nas provas objetivas de escolha múltipla. Esse modelo de prova é um instrumento de medida composto por questões que admitem somente uma resposta previamente definida, o que assegura a impessoalidade do julgamento. Os modelos de prova com resposta aberta objetiva, apesar de permitirem ao aluno desenvolver melhor o raciocínio, podem ter, na correção, critérios subjetivos, mesmo com gabaritos previamente definidos.

O concurso de seleção para residência médica não se propõe a nortear a formatação do currículo da graduação. Pressupõe-se que as faculdades de Medicina estejam adequadas às propostas das Diretrizes Curriculares Nacionais. No entanto, o material obtido no presente estudo pode servir como mais um instrumento para a reflexão das escolas médicas. 
Gráfico 1

Avaliação geral de todas as provas.

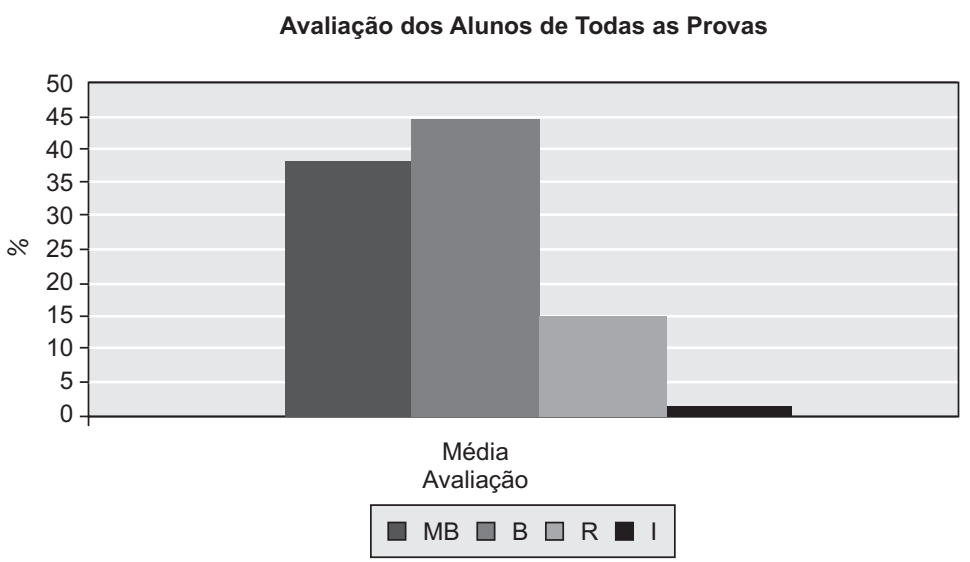

Gráfico 2

Avaliação da prova escrita.

\section{Prova de Escola Múltipla}

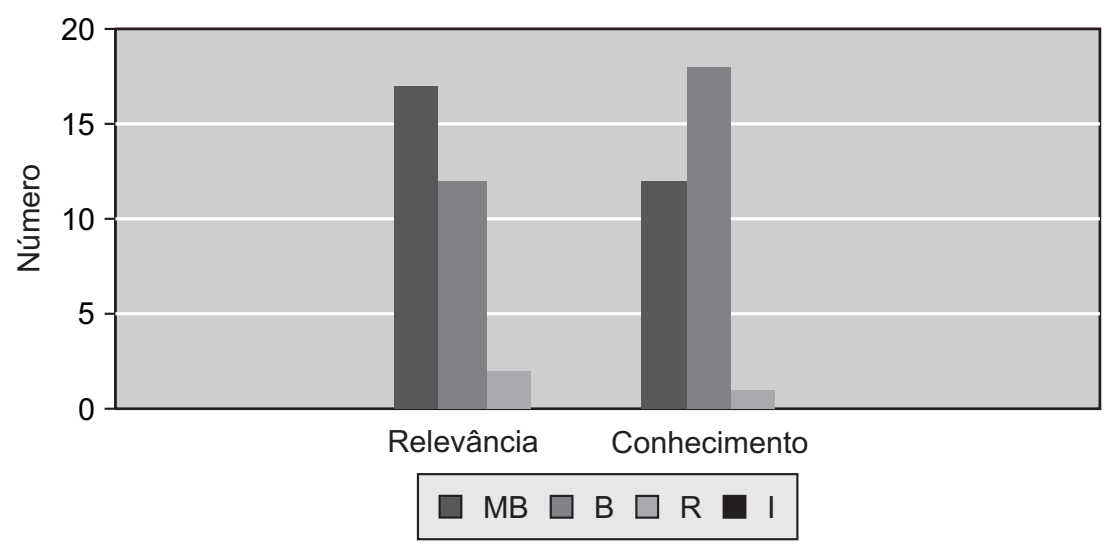

Gráfico 3

Avaliação da prova prática (multimídia) em relação à relevância dos temas.

\section{Relevância}

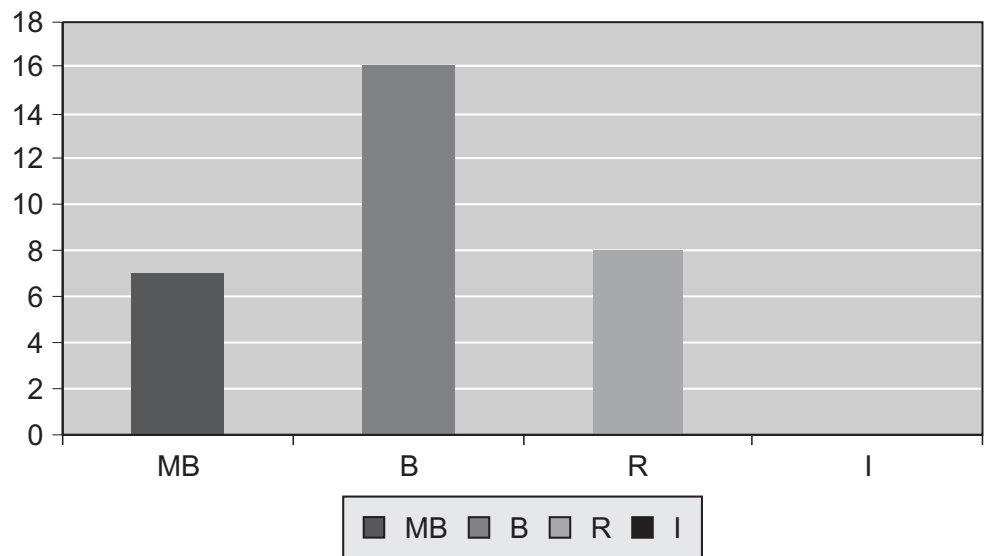




\section{Gráfico 4}

Prova prática (multimídia). Avaliação do conhecimento nas áreas básicas. $\mathrm{CM}$ = Clínica Médica; CG = Cirurgia

Avaliação de Conhjecimento (Multimídia)

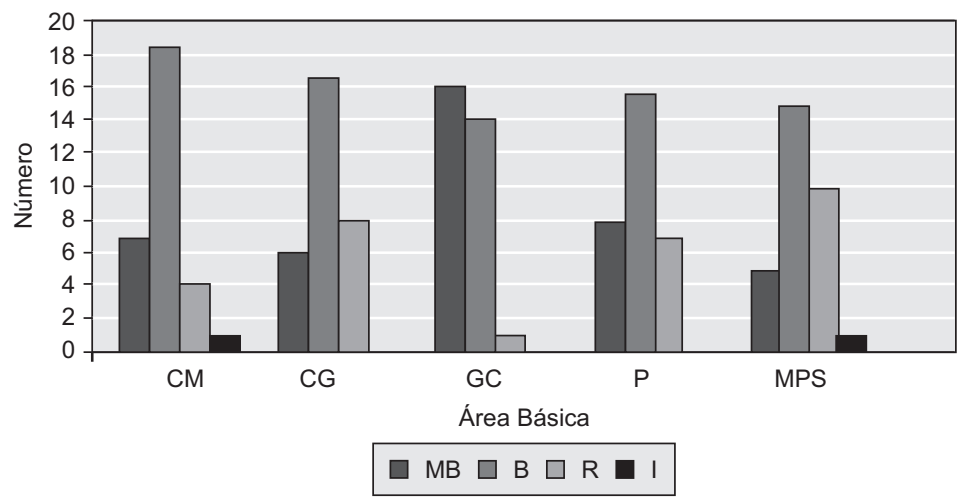

Gráfico 5

Avaliação da prova de habilidades e atitude

Prova de Habilidades e Atitudes

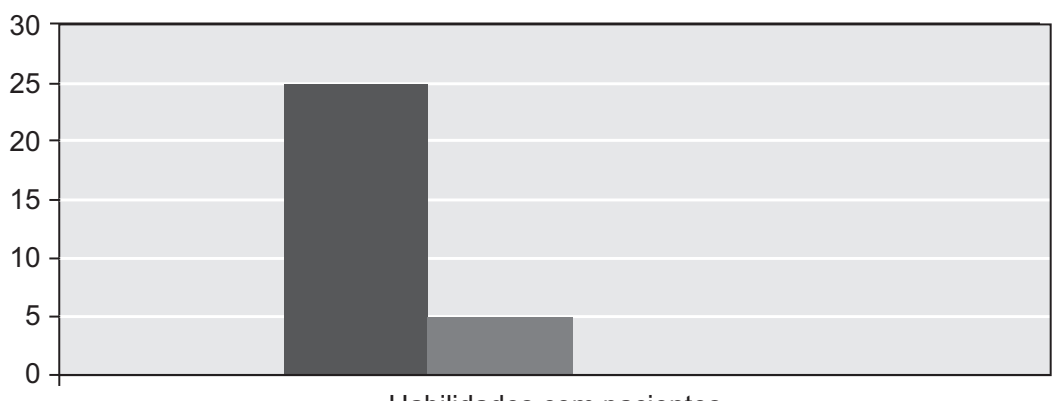

Habilidades com pacientes

MB $\square \mathrm{B} \square \mathrm{R} \square \mathrm{I}$

Em questionário antes aplicado aos participantes de uma oficina no Congresso Brasileiro de Educação Médica (Natal, 2005), foi possível observar a divergência de percepção entre os alunos da graduação médica presentes e os professores e/ou preceptores de médicos residentes. Predomina entre os graduandos o conceito de que o conhecimento é a competência mais importante a ser avaliada na prova prática, enquanto os professores e preceptores dos residentes valorizaram mais a atitude ${ }^{5}$. Os médicos recém-formados, neste estudo atual, consideraram como a melhor avaliação aquela presencial com pacientes. De maneira geral, a opinião dos candidatos em relação às provas de seleção foi de aprovação. Deve-se ressaltar, no entanto, a possibilidade de um viés de seleção decorrente do fato de que os respondentes são candidatos já aprovados no concurso. Por outro lado, esse fato também permite contribuições mais reflexivas, uma vez que não estão mais envolvidos em processo seletivo.

O paradigma inovador, como proposta que reconhece as atuais necessidades sociais na área de saúde, se expressa pela aprendizagem por meio de problemas, centrada no aluno e com uma concepção humanista, ética, generalista e preventiva. Os novos modelos de produção exigem a capacidade de pensar, decidir, ter iniciativa, expressar-se com clareza, ser autônomo. Para este fim, a comissão elegeu alguns temas prevalentes na prova objetiva e provocou desafios em que a não distinção das questões em cada área do conhecimento médico fez com que o candidato evitasse o pensamento fragmentado. Assim, a mesma paciente idosa poderia ter admissão no serviço de emergência (questões de doença na área de Cirurgia Geral ou Clínica Médica?), bem como aconselhamento médico sobre reposição hormonal (questões de saúde relacionadas à área de Ginecologia ou Medicina Preventiva e Social?). Da mesma forma, a gestante com infecção pelo herpes vírus deverá ter uma abordagem obstétrica durante o pré-natal e aconselhamentos preventivos para o parceiro.

A prova com recursos de multimídia foi um projeto inovador em processos seletivos de residência médica. Multimídia é a combinação, controlada por computador, de pelo menos um tipo de mídia estática (texto, fotografi, gráfico), com pelo menos um tipo de mídia dinâmica (vídeo, audio, animação). Aapresen- 
tação da informação se faz de maneira multissensorial, fato que pode exigir a utilização de meios de comunicação que, até há pouco tempo, raramente eram empregados de maneira coordenada, como som (voz humana, música), fotografia (imagem estática), vídeo (imagens dinâmicas), animação, gráficos e textos (incluindo tabelas e gráficos). Esse modelo de avaliação pode ser confundido com o discursivo de respostas objetivas. No entanto, quando essas mesmas informações são contextualizadas numa atividade, numa reflexão, pode-se estabelecer o nexo entre o conhecimento e a tomada de decisão. Talvez esta seja a maior contribuição da modalidade de multimídia para a prova de residência médica.

A prova prática presencial com o paciente dá ao examinador a oportunidade de avaliar a atitude do candidato frente a uma situação real, testar habilidades práticas, formular questões (conhecimento) e explorar soluções (inovação). Esse tipo de avaliação com o paciente é considerado o de maior valor, coincidindo com a opinião dos respondentes ${ }^{6}$. Mas é trabalhosa, extensa, o que pode torná-la inviável para grande parte das instituições. As questões éticas referentes a possível constrangimento dos pacientes podem ser anuladas com consentimento informado.

Morrison ${ }^{7}$, em seu artigo sobre avaliação no ensino médico, faz uma observação acerca da questão ética que envolve os processos de avaliação e a pesquisa. A pesquisa visa à produção generalizada de resultados, que deverão ser publicados na literatura e, portanto, requer submissão ao comitê de ética e consentimento do paciente, quando envolvido no projeto de pesquisa. Os resultados da avaliação do aluno são para uso local e demonstram a produção intelectual daquele candidato. Os candidatos, ao receberem o questionário do presente estudo, foram esclarecidos sobre o objetivo do mesmo, da não obrigatoriedade de resposta e de identificação.

A preocupação da CNRM de estabelecer normas para os processos seletivos a partir da Resolução no 01/99 (DOU 5/7/99) veio do fato de que a flexibilidade e a pouca transparência nos critérios até então utilizados por cada instituição poderiam privilegiar alguns candidatos previamente conhecidos. Esta resolução estipulou peso mínimo de $90 \%$ para provas objetivas, que avaliava conhecimento em Medicina, com número igual de questões para as cinco áreas básicas, e peso máximo de $10 \%$ para prova oral, entrevista ou avaliação curricular. A pontuação impunha maior dificuldade num eventual favorecimento, porém não excluía essa possibilidade, uma vez que décimos de pontos poderiam ser marcadores de fronteiras. Além do mais, o modelo das provas não avaliava outras habilidades importantes na formação médica, desprestigiando todo o aspecto prático que caracteriza a formação acadêmica, sobretudo durante o internato.
A Resolução da Comissão Nacional de Residência Médica preconiza a introdução de mecanismos de seleção que contemplem aspectos referentes à aquisição de habilidades necessárias ao desenvolvimento de atividades essenciais à formação médica mediante prova prática. Propõe que se realize em ambientes sucessivos e se aplique igualmente a todos os candidatos selecionados a partir da prova escrita, envolvendo as cinco grandes áreas do conhecimento médico ${ }^{3}$. A Resolução do Conselho Nacional de Educação (CNE) / Câmara de EducaçãoSuperior (CES) de 2001 ( $n^{\circ} 4$, de novembro de 2001, art. 12, inciso II), recomenda a utilização de metodologias que privilegiem a participação ativa do aluno na construção de conhecimento e a integração entre ensino, pesquisa e extensão/assistência ${ }^{2}$. Quando a comissão de seleção do concurso de residência da UFRJ propôs a combinação de meios visuais aos registros gráficos, a idéia inicial era conjugar ao conhecimento o fenômeno estudado e integrar as disciplinas básicas (ciclo básico da Medicina) à prática, o que foi possível com a prova de multimídia. Neste sentido, entende-se que o concurso para a residência médica de alguma forma responde ao processo de ensino-aprendizagem preconizado pelas diretrizes curriculares.

A Comissão Nacional de Residência Médica, com o apoio da Associação Brasileira de Educação Médica (Abem), promoveu a Oficina Nacional de Prova Prática, durante a qual sete das oito instituições que a empregaram no concurso de seleção apresentaram suas experiências. A discussão abordou aspectos pedagógicos (o impacto da prova prática no perfil do médico selecionado sobre o internato, a preparação dos examinadores e as características institucionais). O segundo aspecto comentado foi a logística e organização e, finalmente, os aspectos legislativos com base na Resoluçãon ${ }^{\circ} 8$ de 2004 da CNRM³ . A prova prática foi realizada principalmente por entidades públicas (93\%), sendo a totalidade vinculada a escolas médicas. Os expositores destacaram a maior interação entre os departamentos e diversos setores da instituição, o que favoreceu a discussão da avaliação durante a graduação. Também foram apontados alguns pontos negativos, como os elevados custos para a realização dessas provas, a longa duração do concurso - o que dificultaria, por exemplo, o deslocamento e a permanência prolongada de candidatos de outros estados - e a falta de padronização, que possibilitaria subjetividade nos critérios de seleção. Considerou-se precoce a análise do impacto na mudança do perfil do selecionado, que depende de outras variáveis, como o perfil da instituição e o conteúdo da prova de escolha múltipla executada na fase preliminar ${ }^{1}$.

No processo de seleção da UFRJ, foi fundamental a interação interdisciplinar para a elaboração de todas as fases do concurso, 
principalmente na elaboração do novo modelo da prova objetiva, que procurou, mediante situações clínicas prevalentes, abordar o conhecimento médico na abrangência das cinco cadeiras básicas, sem distinção das questões de cada uma delas. Considerou-se que, aliada à prova prática, a prova objetiva no formato de escolha múltipla é uma ferramenta largamente aplicada na educação médica e que, quando bem elaborada, pode ser a mais apropriada para concursos públicos que envolvam grande número de candidatos, tendo sido, na opinião destes, bastante satisfatória.

\section{CONCLUSÕES}

O modelo de prova implantado para a seleção de candidatos às vagas para residência médica da UFRJ sem pré-requisito procurou coerência com as Diretrizes Curriculares Nacionais do Curso de Graduação em Medicina. A maioria dos candidatos que respondeu o questionário aprovou as várias etapas do concurso, sendo que a prova prática presencial com o paciente obteve o melhor conceito. Os temas escolhidos para a elaboração da prova escrita foram relevantes, na opinião da maioria. A avaliação de conhecimento, por meio das provas de escolha múltipla e multimídia, obteve bom conceito, na percepção dos candidatos. Os objetivos iniciais da comissão de seleção foram alcançados e convergiram com a opinião dos candidatos.

\section{AGRADECIMENTOS}

Externamos nossos agradecimentos aos demais colaboradores do concurso de seleção de residência médica. Sem eles, este trabalho não poderia ser realizado: Sergio Zaidhaft, Elizabeth Muxfeldt, Maria Lucia Pimentel, Eduardo Gordilho Fraga, Ronaldo Vinagre, Cid Marcos David, Cláudio Machado, Simone Saintive, Kátia Bloch, José Paulo Pereira Junior, Eliana Claudia Otero Ribeiro, José Carlos Conceição, Guilherme Pinto Bravo.

\section{REFERÊNCIAS}

1. Oficina Nacional de Avaliação dos Procedimentos da prova prática aplicada durante o processo seletivo de Residência
Médica.[online]. [acesso em: 13 mar. 2006]. Disponível em: http://portal.mec.gov.br/sesu/arquivos/pdf/cnrm/avalprovapratica.pdf.

2. Brasil. Ministério da Educação. Conselho Nacional de Educação. Minuta da Resolução de 3 de Outubro de 2001. Institui as Diretrizes Curriculares Nacionais do Curso de Graduação em Medicina [online]. [acesso em: $8 \mathrm{dez}$. 2005].Resolução CNE/CES n.4, de 7 de Novembro de 2001. Disponível em: http://portal.mec.gov.br/sesu/arquivos/pdf/0401Medicina.pdf>

3. Brasil. Ministério da Educação. Comissão Nacional de Residência Médica. Resolução 8/2004 da CNRM. Dispõe sobre o processo de seleção pública dos candidatos aos Programas de Residência Médica.[online]. [acesso em: 8 dez. 2005] Publicada no Diário Oficial da União de 13 de agosto de 2004, Seção 1 pág.25.Disponível em: http:// portal.mec.gov.br/sesu.

4. Comissão Nacional de Residência Médica. Resolução CNRM №. 004/2003.

5. Goldwasser R. A prova prática no processo de seleção do concurso de Residência Médica. Rev Bras Educ Méd.2006;30(3):115-124.

6. Rolfe IE, Sanson-Fisher, RW. Translating learning principles into practice: a new strategy for learning clinical skills. Medical Education.2002;36:345-352.

7. Morrison J. ABC of learning and teaching in medicine. Evaluation. BMJ. 2003; 326:385.

\section{CONFLITO DE INTERESSES}

Declarou não haver

\section{ENDEREÇO PARA CORRESPONDÊNCIA}

Rua Guilhermina Guinle, 170 apto701

Botafogo

CEP.: 22270-060 - Rio de Janeiro - RJ

E-mail: gold.rosane@gmail.com 